\title{
Quantitative assessment of the effects of the EPHX1 Tyr113His polymorphism on lung and breast cancer
}

\author{
X. Tan ${ }^{1 *}$, Y.Y. Wang ${ }^{1 *}$, X.Y. Chen ${ }^{2 *}$, L. Xian ${ }^{1}$, J.J. Guo ${ }^{1}$, \\ G.B. Liang ${ }^{1}$ and M.W. Chen ${ }^{1}$ \\ ${ }^{1}$ Department of Cardiothoracic Surgery, First Affiliated Hospital, \\ Guangxi Medical University, Nanning, Guangxi, China \\ ${ }^{2}$ Department of Oncology, First Affiliated Hospital, \\ Guangxi Medical University, Nanning, Guangxi, China \\ *These authors contributed equally to this study. \\ Corresponding author: M.W. Chen \\ E-mail: chen535@126.com
}

Genet. Mol. Res. 13 (3): 7437-7446 (2014)

Received July 12, 2013

Accepted March 9, 2014

Published September 12, 2014

DOI http://dx.doi.org/10.4238/2014.September.12.10

\begin{abstract}
The association between the microsomal epoxide hydrolase 1 gene (EPHX1) Tyr113His polymorphism and lung cancer and breast cancer risk has been reported in many recent studies, but there is no consensus among the results. Thus, we examined the association between the EPHXI Tyr113His polymorphism and lung cancer through a meta-analysis. A comprehensive literature search was performed using the Pubmed and Embase databases. Odds ratios with $95 \%$ confidence intervals were used to assess the strength of associations. Our meta-analysis suggested that the Tyr113His polymorphism was associated with lung cancer risk in Asians under 3 genetic models, including a $\mathrm{C} v s \mathrm{~T}, \mathrm{CC} v s \mathrm{TT}$, and recessive model. However, the risk was decreased in Caucasians under the genetic models, including a $\mathrm{C} v s \mathrm{~T}, \mathrm{CC} v s \mathrm{TT}$, or $\mathrm{CT} v s \mathrm{TT}$, dominant, and recessive model. In contrast, there was no association with breast cancer risk for any of the genetic models. Our meta-analysis suggested that the EPHX1 Tyr113His polymorphism may be a risk factor for lung cancer in Asians, whereas it may
\end{abstract}


be a decreased risk factor among Caucasians. However, this polymorphism was not found to be associated with breast cancer.

Key words: EPHX1; Polymorphism; Lung cancer; Breast cancer; Meta-analysis

\section{INTRODUCTION}

Among human cancers, lung cancer, with a 5-year survival rate less than $14 \%$ for males and less than 18\% for females in most countries (Youlden et al., 2008), is regarded as one of the most common lethal malignancies worldwide. Breast cancer is the most common cancer and the leading cause of death among females, accounting for $23 \%$ of total cancer in females and $14 \%$ of cancer deaths (Jemal et al., 2011). It is well-known that cigarette smoking contributes to an increased risk of lung cancer. In addition, other environmental carcinogens, such as asbestos, arsenic, radon, and polycyclic aromatic hydrocarbons (PAH), may also be considered risk factors for lung cancer and breast cancer (Sangrajrang et al., 2009; Jemal et al., 2011). However, not all exposed individuals develop lung and breast cancers, suggesting that genetic factors play a role in these conditions. Microsomal epoxide hydrolase $(\mathrm{mEH})$ is an important metabolic biotransformation enzyme that catalyzes epoxidation intermediate hydrolysis to trans-dihydrodiols, which can be conjugated and excreted from the body. In certain conditions, trans-dihydrodiols generated from chemical carcinogens, such as PAHs, are highly toxic and mutagenic. Thus, $\mathrm{mEH}$ has a dual effect in the detoxification and activation of procarcinogens, and its role in carcinogenesis may depend on exposure to different environmental substrates (Zhang et al., 2003). The tyrosine to histidine $(\mathrm{T} \rightarrow \mathrm{C})$ replacement in exon 3 (Tyr113His) of the EPHX1enzyme decreased activity by approximately $50 \%$ (Hassett et al., 1994), suggesting that mutations in this gene may lead to cancer.

The EPHX1 gene, which is located on chromosome 1q42.1, has several known variations. These polymorphisms may be associated with prostate cancer, colorectal cancer, and bladder cancer (Mittal and Srivastava, 2007; Liu et al., 2012; Zhang et al., 2012). Previous studies have suggested that the EPHXI Tyr113His polymorphisms associated with the risk for lung cancer and breast cancer. However, the results were unclear. Thus, we performed a meta-analysis to investigate the association between the EPHX1 Tyr113His polymorphism and susceptibility to lung cancer and breast cancer.

\section{MATERIAL AND METHODS}

\section{Search strategy and selection criteria}

All case-control studies were systematically researched from the Pubmed and Embase databases for all medical publications until February 2013 with the following terms: microsomal epoxide hydrolase 1, mEH, EPHX1, EPOX, HYL1, Tyr113His, exon 3, codon113, T113C, rs1051740, polymorphism, variant, and "lung" combined with "carcinoma", "cancer", or "breast", "mammary" combined with "cancer", and "carcinoma". All human studies included in our meta-analysis met the following criteria: full-text articles, case-control design, evaluated the association between the EPHX1 Tyr113His polymorphism and lung cancer or breast cancer risk, odds ratio (OR) with 95\% confidence interval $(95 \% \mathrm{CI})$ with sufficient data for estimating, genotype associations, and the dis- 
tribution of genotypes complied with Hardy-Weinberg equilibrium (HWE) in controls.

\section{Data extraction}

As inclusion criteria, all eligible studies were carefully identified by 2 investigators (X. Tan and Y.Y. Wang) independently. In case of disagreement, a third investigator (M.W. Chen) evaluated the data. Data items included: first author's name, year of publication, country, ethnicity, genotyping method, source of controls, and different genotype numbers in all studies.

\section{Statistical analysis}

The pooled risk (OR) and $95 \% \mathrm{CI}$ were used to assess the strength of the association between the EPHX1 Tyr113His polymorphism and lung cancer or breast cancer for each study. To avoid assuming only one "incorrect" genetic model, there were at least 3 possible genotypes to examine in our meta-analysis. We estimated the OR for the co-dominant model (CC vs TT, CT vs TT), dominant model (CC+CT vs TT), and recessive model (CC vs $\mathrm{CT}+\mathrm{TT})$, respectively.

Between-study heterogeneity was assessed by using the chi-square statistic based on the Q statistical test and its associated $\mathrm{P}$ value (Higgins et al., 2003). A P value $>0.1$ or $I^{2}<$ $25 \%$ indicated no heterogeneity, which was estimated by the fixed effects model with MantelHaenszel's method for the overall gene effect (Mantel and Haenszel, 1959). When $\mathrm{P}<0.1$ or $I^{2}>$ $50 \%$, the heterogeneity was considered to be significant, and the random effects model with the DerSimonian-Laird method was performed (Lau et al., 1997). Sensitivity analysis was conducted to exclude 1 study at a time. HWE was determined by using the Pearson statistic $(\mathrm{P}>0.05)$ for each study (Bosco et al., 2012). Potential publication bias was estimated by Begg's test and Egger's test ( $\mathrm{P}<0.05$ was considered to be statistically significant) (Peters et al., 2006). Owing to geographical and ethnic differences, to evaluate the effects of covariance, subgroup analyses were performed. Ethnic subgroups were divided into Caucasian and Asian. Our analysis was performed using the Stata software version 11.1 (StataCorp; College Station, TX, USA). All P values were 2 -sided, with values less than 0.05 considered to be statistically significant.

\section{RESULTS}

\section{Characteristics of relevant studies}

Using our search strategy and inclusion criteria, 9 studies were excluded because they deviated from HWE. A total of 14 studies (Benhamou et al., 1998; Persson et al., 1999; London et al., 2000; To-Figueras et al., 2001; Wu et al., 2001; Yin et al., 2001; Cajas-Salazar et al., 2003; Gsur et al., 2003; Harms et al., 2004; Liang et al., 2004; Voho et al., 2006; Timofeeva et al., 2010; Ihsan et al., 2011; Tilak et al., 2011) that included full-text articles and complied with HWE demonstrated an association between the EPHX1 Tyr113His polymorphism and lung cancer (Table 1). Among the studies included, 2 included 2 ethnicity types (London et al., 2000; Wu et al., 2001), and the data was collected separately and served as independent studies in our meta-analyses. A total of 16 studies, including 2399 cases and 5623 controls, examined the EPHX1 Tyr113His polymorphism (Table 1). In order to evaluate the effects of covariance, subgroup analyses were performed. Because smoking status and histopathology data were insufficient, we performed subgroup analyses by ethnicity. 
There were 5 studies involving Asians (Persson et al., 1999; Yin et al., 2001; Liang et al., 2004; Ihsan et al., 2011; Tilak et al., 2011), 7 studies on Caucasians (Benhamou et al., 1998; London et al., 2000; To-Figueras et al., 2001; Gsur et al., 2003; Harms et al., 2004; Voho et al., 2006; Timofeeva et al., 2010), and 3 studies on African subjects (London et al., 2000; Wu et al., 2001; Cajas-Salazar et al., 2003). For breast cancer, 1study was excluded because there was not sufficient genotype data (de Assis et al., 2002), and therefore 5 studies (Sarmanová et al., 2004; Spurdle et al., 2007; Khedhaier et al., 2008; Justenhoven et al., 2008; Sangrajrang et al., 2009) including a total of 2943 cases and 2314 controls that examined the association between the EPHX1 Tyr113His polymorphism and breast cancer were included into our meta-analysis (Table 2). In the subgroup analyses by ethnicity, there were 4 studies on Caucasians (Sarmanová et al., 2004; Spurdle et al., 2007; Khedhaier et al., 2008; Justenhoven et al., 2008), whereas there was 1 study on Asians (Sangrajrang et al., 2009).

\begin{tabular}{|c|c|c|c|c|c|c|c|c|c|c|c|c|}
\hline \multirow[t]{2}{*}{ Investigator } & \multirow[t]{2}{*}{ Year } & \multirow[t]{2}{*}{ Race } & \multirow[t]{2}{*}{ Country } & \multicolumn{3}{|c|}{ Case } & \multicolumn{3}{|c|}{ Control } & \multirow[t]{2}{*}{$\mathrm{P}^{\mathrm{a}}$} & \multirow[t]{2}{*}{ Control source } & \multirow[t]{2}{*}{ Methods } \\
\hline & & & & $\mathrm{CC}$ & CT & TT & $\mathrm{CC}$ & CT & $\mathrm{TT}$ & & & \\
\hline Tilak et al. & 2011 & Asian & India & 28 & 85 & 62 & 31 & 157 & 134 & 0.12 & HB & PCR \\
\hline Ihsan et al. & 2011 & Asian & India & 55 & 51 & 82 & 63 & 133 & 94 & 0.21 & PB & PCR-RFLP \\
\hline Timofeeva et al. & 2010 & Caucasian & Germany & 57 & 238 & 316 & 119 & 520 & 627 & 0.45 & PB & MALDI-TOFMS \\
\hline Voho et al. & 2006 & Caucasian & Finland & 13 & 81 & 133 & 189 & 865 & 1029 & 0.70 & PB & PCR-RFLP \\
\hline Liang et al. & 2004 & Asian & China & 29 & 87 & 36 & 28 & 76 & 48 & 0.82 & $\mathrm{HB}$ & PCR \\
\hline Harms et al. & 2004 & Caucasian & USA & 6 & 37 & 67 & 5 & 52 & 62 & 0.14 & HB & PCR \\
\hline Gsur et al. & 2003 & Caucasian & Austria & 16 & 114 & 147 & 54 & 218 & 224 & 0.92 & HB & PCR \\
\hline Cajas-Salazar et al. & 2003 & African & American & 6 & 37 & 67 & 5 & 52 & 62 & 0.14 & HB & PCR \\
\hline Yin et al. & 2001 & Asian & China & 15 & 54 & 15 & 14 & 46 & 24 & 0.30 & HB & PCR \\
\hline Wu et al. & 2001 & Mixed & USA & 5 & 26 & 20 & 7 & 29 & 28 & 0.90 & PB & PCR \\
\hline Wu et al. & 2001 & African & USA & 3 & 22 & 40 & 4 & 20 & 38 & 0.54 & PB & PCR \\
\hline To-Figueras et al. & 2001 & Caucasian & Spain & 8 & 70 & 97 & 15 & 85 & 87 & 0.35 & PB & PCR \\
\hline London et al. & 2000 & Caucasian & USA & 15 & 82 & 85 & 37 & 184 & 237 & 0.87 & PB & PCR \\
\hline London et al. & 2000 & African & USA & 1 & 48 & 106 & 12 & 77 & 153 & 0.56 & PB & PCR \\
\hline Persson et al. & 1999 & Asian & China & 20 & 33 & 21 & 22 & 59 & 41 & 0.92 & PB & PCR \\
\hline Benhamou et al. & 1998 & Caucasian & France & 22 & 46 & 82 & 31 & 77 & 64 & 0.35 & $\mathrm{HB}$ & PCR \\
\hline
\end{tabular}

$\mathrm{P}^{\mathrm{a}}$ for Hardy-Weinberg equilibrium in control group; $\mathrm{HB}=$ hospital-based; $\mathrm{PB}=$ population-based; $\mathrm{PCR}=$ polymerase chain reaction; PCR-RFLP = polymerase chain reaction restriction fragment length polymorphism; MALDI-TOFMS = matrix-assisted laser desorption/ionization time-of-flight mass spectrometry.

Table 2. Studies summary of EPHX1 Tyr113His polymorphism with breast cancer.

\begin{tabular}{|c|c|c|c|c|c|c|c|c|c|c|c|}
\hline \multirow[t]{2}{*}{ Investigator } & \multirow[t]{2}{*}{ Year } & \multirow[t]{2}{*}{ Race } & \multirow[t]{2}{*}{ Country } & \multicolumn{3}{|c|}{ Case } & \multicolumn{3}{|c|}{ Control } & \multirow[t]{2}{*}{ Control source } & \multirow[t]{2}{*}{ Methods } \\
\hline & & & & $\mathrm{CC}$ & $\mathrm{CT}$ & $\mathrm{TT}$ & $\mathrm{CC}$ & $\mathrm{CT}$ & $\mathrm{TT}$ & & \\
\hline Sarmanová et al. & 2004 & Caucasian & Czech Republic & 45 & 77 & 115 & 39 & 124 & 148 & HB & PCR-RFLP \\
\hline Spurdle et al. & 2007 & Caucasian & Australian & 103 & 496 & 639 & 85 & 262 & 316 & PB & PCR \\
\hline Khedhaier et al. & 2008 & Caucasian & Tunisia & 38 & 119 & 149 & 16 & 115 & 113 & PB & PCR-RFLP \\
\hline Justenhoven et al. & 2008 & Caucasian & Germany & 63 & 246 & 296 & 45 & 269 & 295 & PB & MALDI-TOF MS \\
\hline Sangrajrang et al. & 2009 & Asian & Thailand & 128 & 286 & 143 & 115 & 247 & 125 & HB & PCR \\
\hline
\end{tabular}

$\mathrm{HB}=$ hospital-based; $\mathrm{PB}=$ population-based; $\mathrm{PCR}=$ polymerase chain reaction; PCR-RFLP = polymerase chain reaction restriction fragment length polymorphism; MALDI-TOFMS = matrix-assisted laser desorption/ionization time-of-flight mass spectrometry.

\section{Meta-analysis results}

The main results of the meta-analysis regarding the association between the EPHX1 Tyr113His polymorphism and breast cancer risk are shown in Table 3. Results for lung cancer are shown in Table 4. When all studies were pooled, we performed analyses using fixed-effects models if the $Q$-test for heterogeneity was not considered to be significant; otherwise, we used random-effects models. 


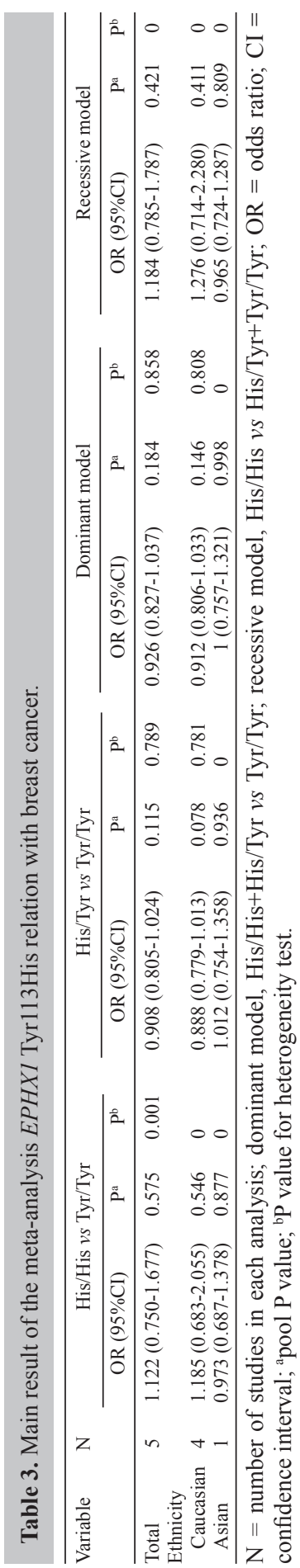


Our meta-analysis showed no evidence for an association between the EPHX1 Tyr113His polymorphism and lung cancer risk in overall studies (Table 4). To determine covariance effects, ethnicity was examined in subgroup analyses. We detected no significant genetic models for African and mixed race populations (Table 4). Interestingly, significant evidence was found for Asians, showing that the low-activity allele (C) of EPHX1 Tyr113His was associated with an increased risk of lung cancer $(\mathrm{C} v s \mathrm{~T}, \mathrm{OR}=1.159,95 \% \mathrm{CI}=1.006$ 1.335, $\mathrm{P}=0.042$ ). In addition, 2 other genetic models revealed a risk relationship with lung cancer in Asians $\left(\mathrm{CC} v s \mathrm{TT}, \mathrm{OR}=1.391,95 \% \mathrm{CI}=1.046-1.850, \mathrm{P}=0.023 ; \mathrm{CC} v_{s} \mathrm{CT}+\mathrm{TT}\right.$, OR $=1.421,95 \% \mathrm{CI}=1.103-1.829, \mathrm{P}=0.006)($ Figure 1 , Table 4$)$. However, we obtained opposite results showing that the EPHX1 Tyr113His polymorphism may be a decreased risk factor in Caucasians for all genetic models examined (Figure 2, Table 4).

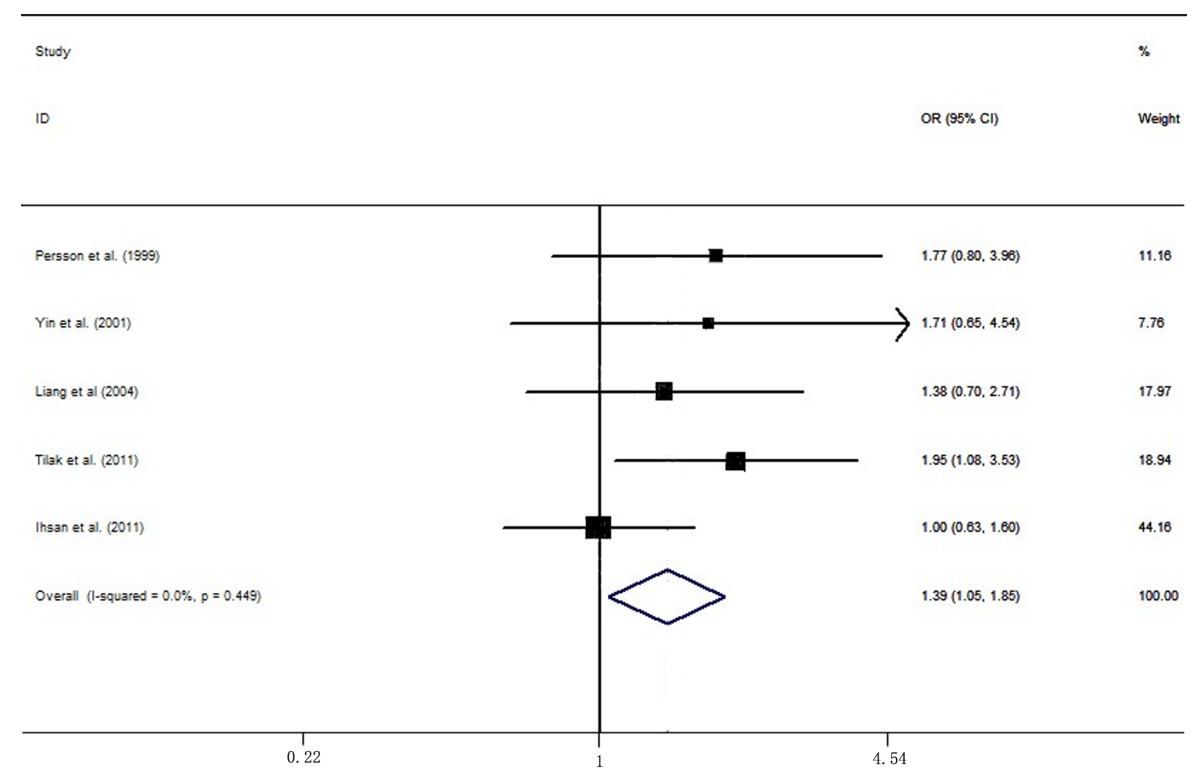

Figure 1. Forest plots for the EPHX1 Tyr113His polymorphism and risk of lung cancer in Asian using the fixedeffect co-dominant model (CC $v s$ TT).

In the overall analysis, no association of $E P H X 1$ Tyr113His with risk for breast cancer was found $(\mathrm{CC} v s \mathrm{TT}, \mathrm{OR}=1.122,95 \% \mathrm{CI}=0.750-1.677, \mathrm{P}=0.575$; $\mathrm{CT} v s \mathrm{TT}, \mathrm{OR}=0.908$, $95 \% \mathrm{CI}=0.805-1.024, \mathrm{P}=0.115$; dominant model, $\mathrm{OR}=0.926,95 \% \mathrm{CI}=0.827-1.037, \mathrm{P}=$ 0.184 ; recessive model, $\mathrm{OR}=1.184,95 \% \mathrm{CI}=0.785-1.787, \mathrm{P}=0.421$ ) (Figure 3, Table 3). Similarly, there was no association for the risk of breast cancer in Caucasians and Asians (Table 3).

\section{Sensitive analysis and test for publication bias}

Sensitivity analysis was performed in our meta-analysis. Upon omitting studies one at a time, the results of reanalyses for the $E P H X 1$ Tyr113His polymorphism and lung cancer and breast cancer became stable, indicating that our meta-analysis results were reliable and robust (data not shown). 


\begin{tabular}{|c|c|c|c|c|c|c|}
\hline \multirow[t]{2}{*}{ Contrast Model } & \multirow[t]{2}{*}{ Studies } & \multicolumn{2}{|c|}{ Odds ratio } & \multirow[t]{2}{*}{$\mathrm{P}^{\mathrm{b}}$} & \multirow[t]{2}{*}{$\mathrm{I}^{2}(\%)$} & \multirow[t]{2}{*}{ Model } \\
\hline & & OR $(95 \% \mathrm{CI})$ & $\mathrm{P}^{\mathrm{a}}$ & & & \\
\hline \multicolumn{7}{|l|}{ Total studies } \\
\hline $\mathrm{C} v s \mathrm{~T}$ & 16 & $0.920(0.818-1.036)$ & 0.169 & 0.003 & $56.20 \%$ & Random $^{\mathrm{c}}$ \\
\hline $\mathrm{CC} v s \mathrm{TT}$ & 16 & $0.888(0.753-1.047)$ & 0.158 & 0.013 & $49.50 \%$ & Fixed $^{\mathrm{d}}$ \\
\hline $\mathrm{CT} v s \mathrm{TT}$ & 16 & $0.865(0.730-1.025)$ & 0.095 & 0.002 & $58.10 \%$ & Random \\
\hline $\mathrm{CC}+\mathrm{TC} v s \mathrm{TT}$ & 16 & $0.876(0.748-1.027)$ & 0.103 & 0.003 & $57.00 \%$ & Random \\
\hline $\mathrm{CC} v s \mathrm{TC}+\mathrm{TT}$ & 16 & $0.973(0.834-1.136)$ & 0.729 & 0.044 & $41.10 \%$ & Fixed \\
\hline \multicolumn{7}{|l|}{ Caucasians } \\
\hline $\mathrm{C} v s \mathrm{~T}$ & 7 & $0.815(0.702-0.946)$ & 0.007 & 0.03 & $56.90 \%$ & Random \\
\hline $\mathrm{CC} v s \mathrm{TT}$ & 7 & $0.720(0.580-0.895)$ & 0.003 & 0.141 & $37.80 \%$ & Fixed \\
\hline $\mathrm{CT} v s \mathrm{TT}$ & 7 & $0.794(0.656-0.962)$ & 0.018 & 0.047 & $53.00 \%$ & Random \\
\hline $\mathrm{CC}+\mathrm{TC}$ vs TT & 7 & $0.774(0.638-0.940)$ & 0.01 & 0.025 & $58.50 \%$ & Random \\
\hline $\mathrm{CC} v s \mathrm{TC}+\mathrm{TT}$ & 7 & $0.793(0.643-0.978)$ & 0.03 & 0.329 & $13.20 \%$ & Fixed \\
\hline \multicolumn{7}{|l|}{ Asians } \\
\hline $\mathrm{C} v s \mathrm{~T}$ & 5 & $1.159(1.006-1.335)$ & 0.042 & 0.38 & $4.80 \%$ & Fixed \\
\hline $\mathrm{CC} v s \mathrm{TT}$ & 5 & $1.391(1.046-1.850)$ & 0.023 & 0.449 & $0.00 \%$ & Fixed \\
\hline $\mathrm{CT} v s \mathrm{TT}$ & 5 & $1.066(0.631-1.801)$ & 0.812 & 0.001 & $79.20 \%$ & Random \\
\hline $\mathrm{CC}+\mathrm{TC} v s \mathrm{TT}$ & 5 & $1.177(0.788-1.760)$ & 0.426 & 0.011 & $69.20 \%$ & Random \\
\hline $\mathrm{CC} v s \mathrm{TC}+\mathrm{TT}$ & 5 & $1.421(1.103-1.829)$ & 0.006 & 0.647 & $0.00 \%$ & Fixed \\
\hline \multicolumn{7}{|l|}{ Africans } \\
\hline $\mathrm{C} v s \mathrm{~T}$ & 3 & $0.793(0.615-1.023)$ & 0.074 & 0.768 & $0.00 \%$ & Fixed \\
\hline $\mathrm{CC} v s \mathrm{TT}$ & 3 & $0.509(0.229-1.134)$ & 0.099 & 0.165 & $44.40 \%$ & Fixed \\
\hline $\mathrm{CT} v s \mathrm{TT}$ & 3 & $0.834(0.612-1.137)$ & 0.251 & 0.553 & $0.00 \%$ & Fixed \\
\hline $\mathrm{CC}+\mathrm{TC}$ vs $\mathrm{TT}$ & 3 & $0.792(0.586-1.069)$ & 0.128 & 0.743 & $0.00 \%$ & Fixed \\
\hline $\mathrm{CC} v s \mathrm{TC}+\mathrm{TT}$ & 3 & $0.594(0.164-2.153)$ & 0.428 & 0.131 & $50.80 \%$ & Random \\
\hline
\end{tabular}

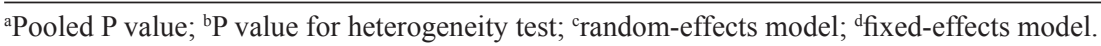

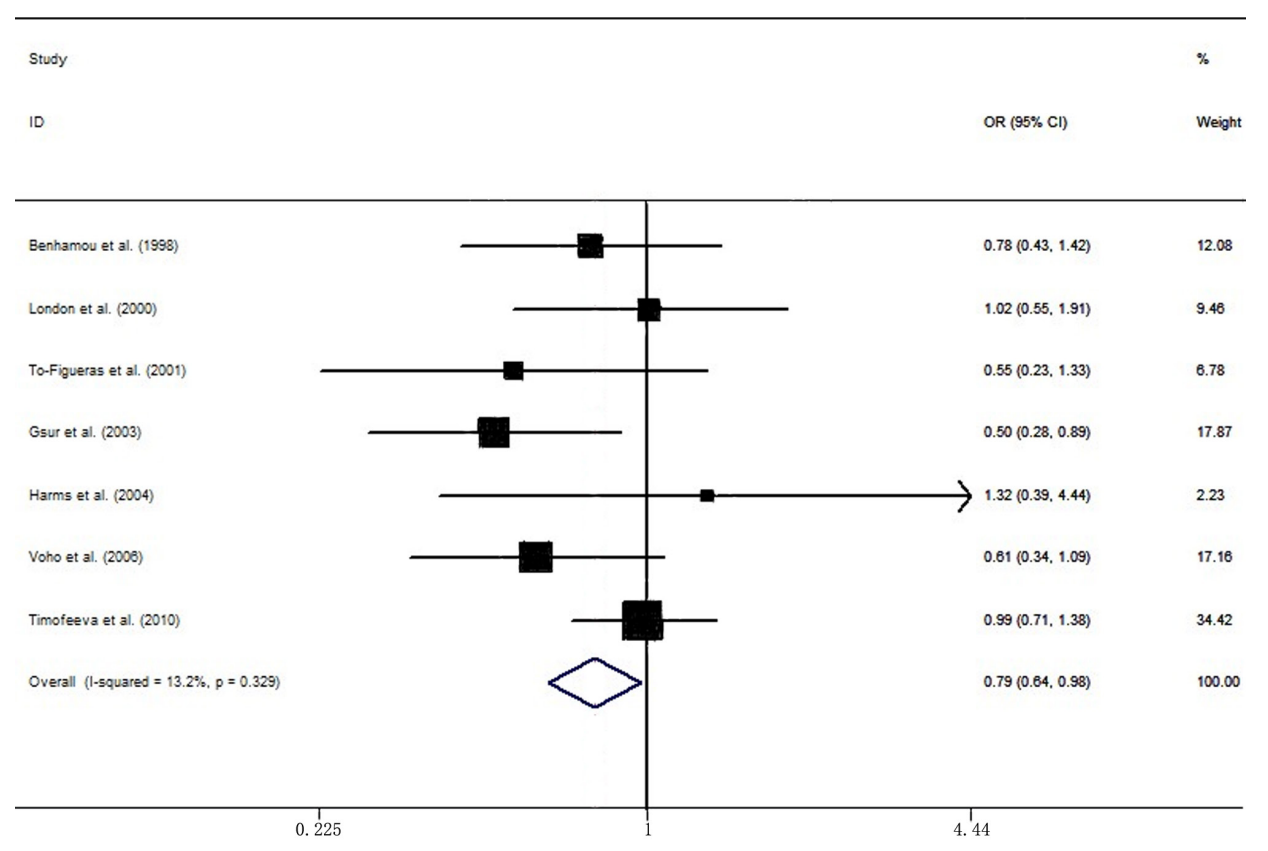

Figure 2. Forest plots for the EPHX1 Tyr113His polymorphism and risk of lung cancer in Caucasians using the fixed-effect recessive model (CC $\left.v_{s} \mathrm{CT}+\mathrm{TT}\right)$. 


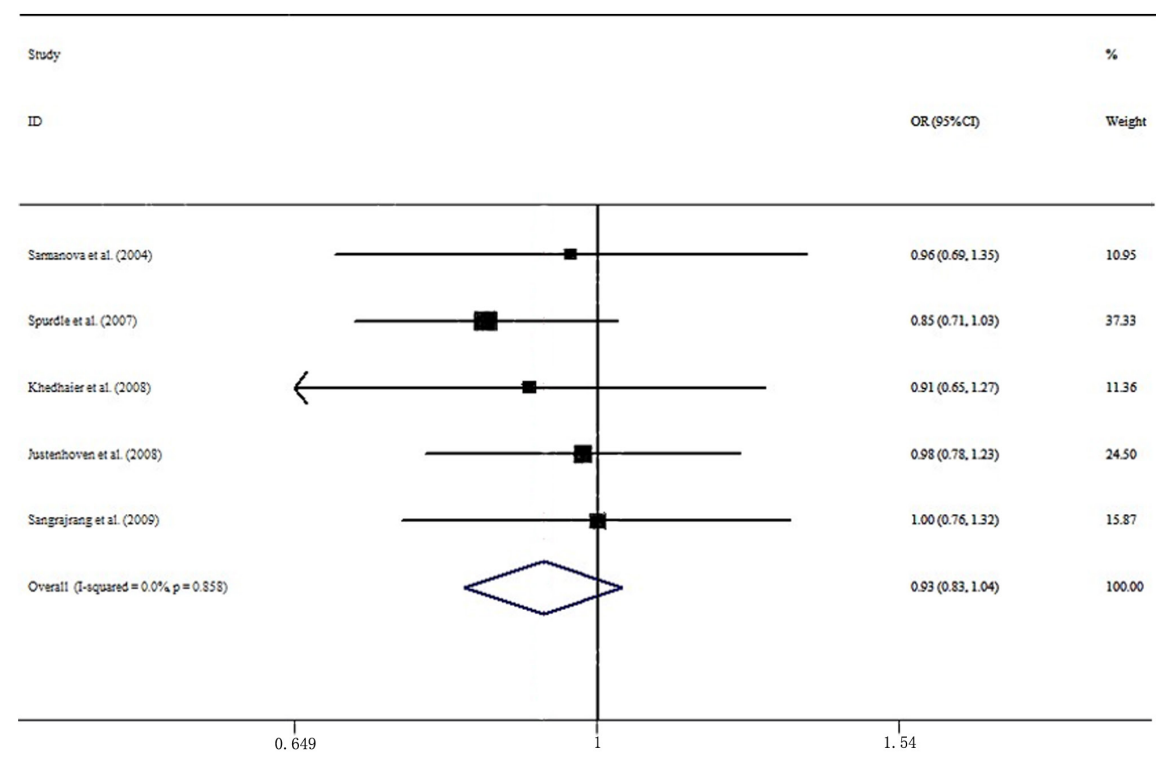

Figure 3. Forest plots for the EPHX1 Tyr113His polymorphism and risk of breast cancer in all studies using the fixed-effect dominant model $(\mathrm{CC}+\mathrm{CT}$ vs TT).

Estimation of publication bias was determined using the Begg and Egger tests. For all studies, the Egger test indicated no evidence of publication bias for lung cancer (CC vs TT Egger's test, $\mathrm{P}=0.691$; CT $v$ s TT Egger's test, $\mathrm{P}=0.734$; recessive model, Egger's test, $\mathrm{P}=$ 0.579 ; dominant model, Egger's test, $\mathrm{P}=0.975)$ or for breast cancer ( $\mathrm{CC} v s$ TT Egger's test, $\mathrm{P}$ $=0.065$; CT vs TT Egger's test, $\mathrm{P}=0.263$; recessive model, Egger's test, $\mathrm{P}=0.090$; dominant model, Egger's test, $\mathrm{P}=0.369$ ) (Begg's data not shown).

\section{DISCUSSION}

EPHX1 is a crucial enzyme in xenobiotic metabolism, which plays an important role in both the activation and detoxification of PAHs and aromatic amines (Liu et al., 2012). The EPHX1 Tyr113His mutation may modify the susceptibility to lung and breast cancers.

The overall OR for the pooled studies revealed no statistically significant association between the Tyr113His polymorphism and lung cancer. Stratified analyses were performed by ethnicity, and no significant association with lung cancer was found for the EPHX1 Tyr113His polymorphism in Africans and mixed ethnicity subjects. However, our meta-analysis indicated that the Tyr113His polymorphism increases the risk of lung cancer in Asians, but decreases the risk in Caucasians. A recent meta-analysis showed similar results (Wang et al., 2013), although some studies were excluded because they deviated from HWE. Lee et al. (2002) suggested a decreased risk for lung cancer with the exon 3 His/His genotype, which was partially consistent with our results. However, the results remain controversial and inconclusive. This may be due to gene-gene interactions that show significant differences for various ethnicities. Furthermore, gene-environment interactions may play an important role in the susceptibility to lung cancer. $\mathrm{PAH}$ and tobacco-specific nitrosamines or other substrates have been suggested to be associ- 
ated with the genotype His113His. An imbalance in carcinogen metabolism may increase the susceptibility to lung cancer (Tilak et al., 2011). In contrast, low activity of the His 113 allele because of conversion is decreased, decreasing lung cancer susceptibility (Voho et al., 2006).

For breast cancer, this is the first systematic review to investigate the association between the EPHX1 Tyr113His polymorphism and breast cancer. No significant association was observed between these factors under any of the genetic models examined. de Assis et al. (2002) first reported that there was no significant association between the EPHXI Tyr113His polymorphism and breast cancer with menopausal or smoking status. Spurdle et al. (2007) suggested that there was a decreased risk associated with the EPHXI CC genotype. However, Khedhaier et al. (2008) showed that the EPHX1 Tyr113His homozygous mutant genotype was significantly associated with breast cancer, particularly in premenopausal patients. This may have been due to low sample size or some other potentially confounding factors such as smoking status, menopausal status, occupation, or lifestyle. Overall, the carcinogenic mechanism is not completely clear.

The Begg and Egger tests did not reveal any publication bias in this meta-analysis, indicating that our meta-analysis conclusions are credible. Heterogeneity significantly affects the results of meta-analysis, and therefore exploring the source of heterogeneity is very important. When we performed stratified analyses by ethnicity, heterogeneity was clearly decreased. This may be an important source of heterogeneity.

Several limitations should be noted for our meta-analysis. First, our results were based on unadjusted estimates, and a well-designed study should be adjusted by age, smoking status, occupation, and lifestyle, among other factors. Insufficient information can cause serious confounding bias. Second, the sample size in our study was very small, and therefore the results should be interpreted with caution. Future studies involving larger samples are recommended to clarify the association. Third, different genotyping methods, such as matrix-assisted laser desorption ionization-time-of-flight mass spectrometry and polymerase chain reaction-restriction fragment length polymorphism, may affect the results. Finally, we did not conduct further studies regarding gene-gene and gene-environment interactions, which may play an important role in lung cancer and breast cancer susceptibility.

In conclusion, this meta-analysis indicated that the EPHX1 Tyr113His polymorphism is associated with an increased risk of lung cancer in Asians, whereas it is associated with a decreased risk in Caucasians. In addition, we found no evidence for an association between the EPHX1 Tyr113His polymorphism and breast cancer risk. Because our data is limited, a larger sample size should be examined using case-control studies for further confirmation.

\section{REFERENCES}

Benhamou S, Reinikainen M, Bouchardy C, Dayer P, et al. (1998). Association between lung cancer and microsomal epoxide hydrolase genotypes. Cancer Res. 58: 5291-5293.

Bosco F, Castro D and Briones MR (2012). Neutral and stable equilibria of genetic systems and the hardy-weinberg principle: limitations of the chi-square test and advantages of auto-correlation functions of allele frequencies. Front Genet. 3: 276.

Cajas-Salazar N, Au WW, Zwischenberger JB, Sierra-Torres CH, et al. (2003). Effect of epoxide hydrolase polymorphisms on chromosome aberrations and risk for lung cancer. Cancer Genet. Cytogenet. 145: 97-102.

de Assis S, Ambrosone CB, Wustrack S, Krishnan S, et al. (2002). Microsomal epoxide hydrolase variants are not associated with risk of breast cancer. Cancer Epidemiol. Biomarkers Prev. 11: 1697-1698.

Gsur A, Zidek T, Schnattinger K, Feik E, et al. (2003). Association of microsomal epoxide hydrolase polymorphisms and lung cancer risk. Br. J. Cancer 89: 702-706. 
Harms C, Salama SA, Sierra-Torres CH, Cajas-Salazar N, et al. (2004). Polymorphisms in DNA repair genes, chromosome aberrations, and lung cancer. Environ. Mol. Mutagen. 44: 74-82.

Hassett C, Aicher L, Sidhu JS and Omiecinski CJ (1994). Human microsomal epoxide hydrolase: genetic polymorphism and functional expression in vitro of amino acid variants. Hum. Mol. Genet. 3: 421-428.

Higgins JP, Thompson SG, Deeks JJ and Altman DG (2003). Measuring inconsistency in meta-analyses. BMJ 327: 557-560.

Ihsan R, Chauhan PS, Mishra AK, Yadav DS, et al. (2011). Multiple analytical approaches reveal distinct gene-environment interactions in smokers and non smokers in lung cancer. PLoS One 6: e29431.

Jemal A, Bray F, Center MM, Ferlay J, et al. (2011). Global cancer statistics. CA Cancer J. Clin. 61: 69-90.

Justenhoven C, Hamann U, Schubert F, Zapatka M, et al. (2008). Breast cancer: a candidate gene approach across the estrogen metabolic pathway. Breast Cancer Res. Treat. 108: 137-149.

Khedhaier A, Hassen E, Bouaouina N, Gabbouj S, et al. (2008). Implication of Xenobiotic Metabolizing Enzyme gene (CYP2E1, CYP2C19, CYP2D6, mEH and NAT2) polymorphisms in breast carcinoma. BMC Cancer 8: 109.

Lau J, Ioannidis JP and Schmid CH (1997). Quantitative synthesis in systematic reviews. Ann. Intern. Med. 127: 820-826.

Lee WJ, Brennan P, Boffetta P, London SJ, et al. (2002). Microsomal epoxide hydrolase polymorphisms and lung cancer risk: a quantitative review. Biomarkers 7: 230-241.

Liang GY, Pu YP and Yin LH (2004). Studies of the genes related to lung cancer susceptibility in Nanjing Han population, China. Yi Chuan 26: 584-588.

Liu F, Yuan D, Wei Y, Wang W, et al. (2012). Systematic review and meta-analysis of the relationship between EPHXI polymorphisms and colorectal cancer risk. PLoS One 7: e43821.

London SJ, Smart J and Daly AK (2000). Lung cancer risk in relation to genetic polymorphisms of microsomal epoxide hydrolase among African-Americans and Caucasians in Los Angeles County. Lung Cancer 28: 147-155.

Mantel N and Haenszel W (1959). Statistical aspects of the analysis of data from retrospective studies of disease. J. Natl. Cancer Inst. 22: 719-748.

Mittal RD and Srivastava DL (2007). Cytochrome P4501A1 and microsomal epoxide hydrolase gene polymorphisms: gene-environment interaction and risk of prostate cancer. DNA Cell Biol. 26: 791-798.

Persson I, Johansson I, Lou YC, Yue QY, et al. (1999). Genetic polymorphism of xenobiotic metabolizing enzymes among Chinese lung cancer patients. Int. J. Cancer 81: 325-329.

Peters JL, Sutton AJ, Jones DR, Abrams KR, et al. (2006). Comparison of two methods to detect publication bias in metaanalysis. JAMA 295: 676-680.

Sangrajrang S, Sato Y, Sakamoto H, Ohnami S, et al. (2009). Genetic polymorphisms of estrogen metabolizing enzyme and breast cancer risk in Thai women. Int. J. Cancer 125: 837-843.

Sarmanová J, Susova S, Gut I, Mrhalova M, et al. (2004). Breast cancer: role of polymorphisms in biotransformation enzymes. Eur. J. Hum. Genet. 12: 848-854.

Spurdle AB, Chang JH, Byrnes GB, Chen X, et al. (2007). A systematic approach to analysing gene-gene interactions: polymorphisms at the microsomal epoxide hydrolase EPHX and glutathione S-transferase GSTM1, GSTT1, and GSTP1 loci and breast cancer risk. Cancer Epidemiol. Biomarkers Prev. 16: 769-774.

Tilak AR, Kumar S, Jain M, Pant MC, et al. (2011). Association of functionally important polymorphism of microsomal epoxide hydrolase gene (EPHXI) with lung cancer susceptibility. Cancer Invest. 29: 411-418.

Timofeeva M, Kropp S, Sauter W, Beckmann L, et al. (2010). Genetic polymorphisms of MPO, GSTT1, GSTM1, GSTP1, EPHXI and NQO1 as risk factors of early-onset lung cancer. Int. J. Cancer 127: 1547-1561.

To-Figueras J, Gene M, Gomez-Catalan J, Pique E, et al. (2001). Lung cancer susceptibility in relation to combined polymorphisms of microsomal epoxide hydrolase and glutathione S-transferase P1. Cancer Lett. 173: 155-162.

Voho A, Metsola K, Anttila S, Impivaara O, et al. (2006). EPHX1 gene polymorphisms and individual susceptibility to lung cancer. Cancer Lett. 237: 102-108.

Wang S, Zhu J, Zhang R, Wang S, et al. (2013). Association between microsomal epoxide hydrolase 1 T113C polymorphism and susceptibility to lung cancer. Tumour. Biol. 34: 1045-1052.

Wu X, Gwyn K, Amos CI, Makan N, et al. (2001). The association of microsomal epoxide hydrolase polymorphisms and lung cancer risk in African-Americans and Mexican-Americans. Carcinogenesis 22: 923-928.

Yin L, Pu Y, Liu TY, Tung YH, et al. (2001). Genetic polymorphisms of NAD(P)H quinone oxidoreductase, CYP1A1 and microsomal epoxide hydrolase and lung cancer risk in Nanjing, China. Lung Cancer 33: 133-141.

Youlden DR, Cramb SM and Baade PD (2008). The International Epidemiology of Lung Cancer: geographical distribution and secular trends. J. Thorac. Oncol. 3: 819-831.

Zhang JH, Jin X, Li Y, Wang R, et al. (2003). Epoxide hydrolase Tyr113His polymorphism is not associated with susceptibility to esophageal squamous cell carcinoma in population of North China. World J. Gastroenterol. 9: 2654-2657.

Zhang Z, Yu XY, Zhang GJ, Guo KF, et al. (2012). Low microsomal epoxide hydrolase expression is associated with bladder carcinogenesis and recurrence. Asian Pac. J. Cancer Prev. 13: 521-525. 